\title{
A Simple Field Leach Test to Assess Potential Leaching of Soluble Constituents from Mine Wastes, Soils, and Other Geologic Materials
}

\section{Introduction}

Rainwater- or snowmelt-induced leaching of major elements, trace elements, and acid from mine wastes or naturally mineralized areas and the effects of the resulting runoff on adjacent streams (fig. 1) are common environmental concerns. Another concern is the direct or indirect uptake of potentially toxic metals from these leachates into the food chain (fig. 2).

Many other geogenic materials (for example, soils, mineralized rocks, dusts, volcanic ash, and forest-fire ash) may also react chemically with water to produce leachates with increased concentrations of major and trace elements and altered $\mathrm{pH}$. Because of this potential, it is important to have a tool that will aid the environmental

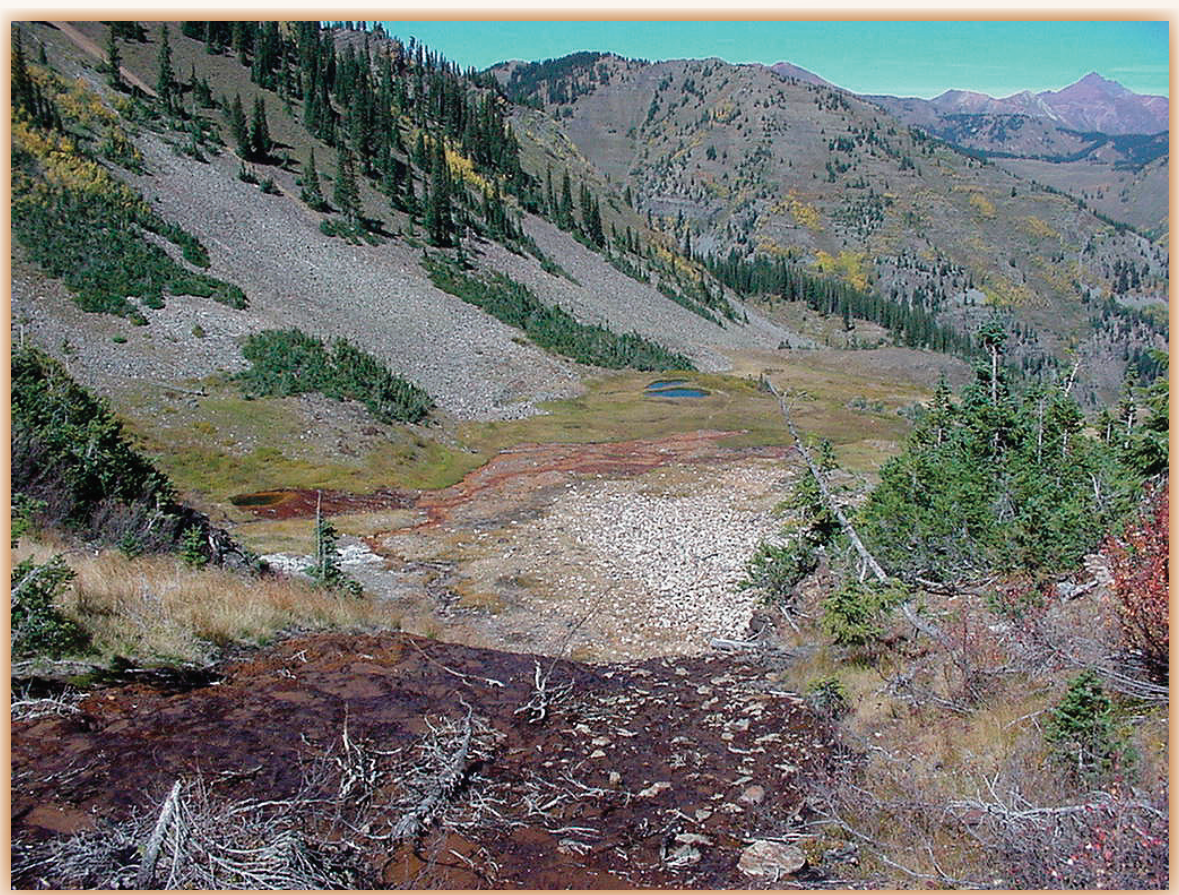

Figure 1. Leached constituents from mineralized areas may affect local streams and biota.

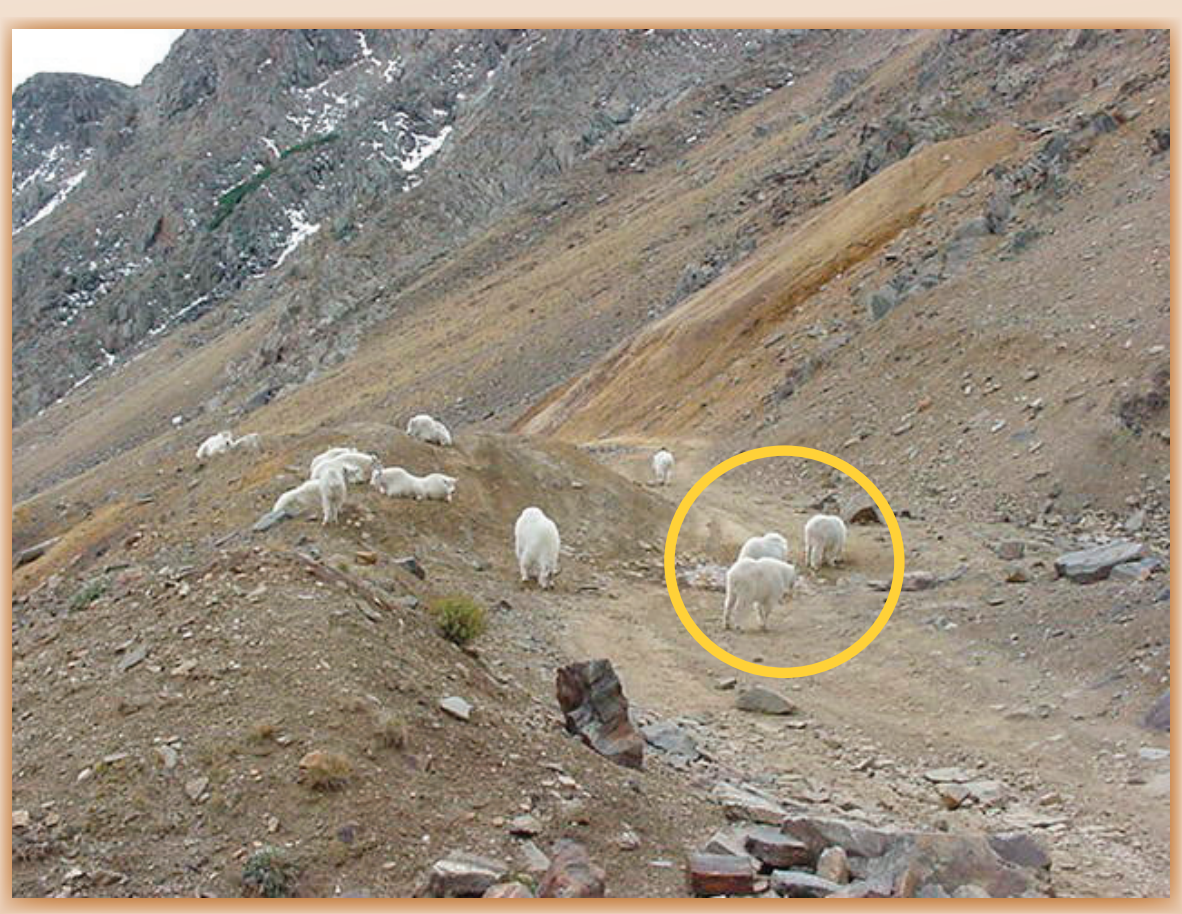

Figure 2. Mountain goats drink rainfall-induced leachate at a historical mine dump in Colorado. scientist in quantifying and understanding the leachability of geologically derived material and the chemical reactions that can occur when the material comes into contact with water.

Traditionally, laboratory leach studies have been a useful way to assess the potential effects from the leaching of materials. However, the leach tests most commonly used are complicated and time consuming and require specialized equipment. In light of these factors, the U.S. Geological Survey (USGS) has developed a fast (5-minute), relatively simple and cost-effective leach test. The USGS Field Leach Test (FLT) can easily be performed in the laboratory or onsite to effectively simulate the chemical reactions that occur when geologic materials are leached by water. 


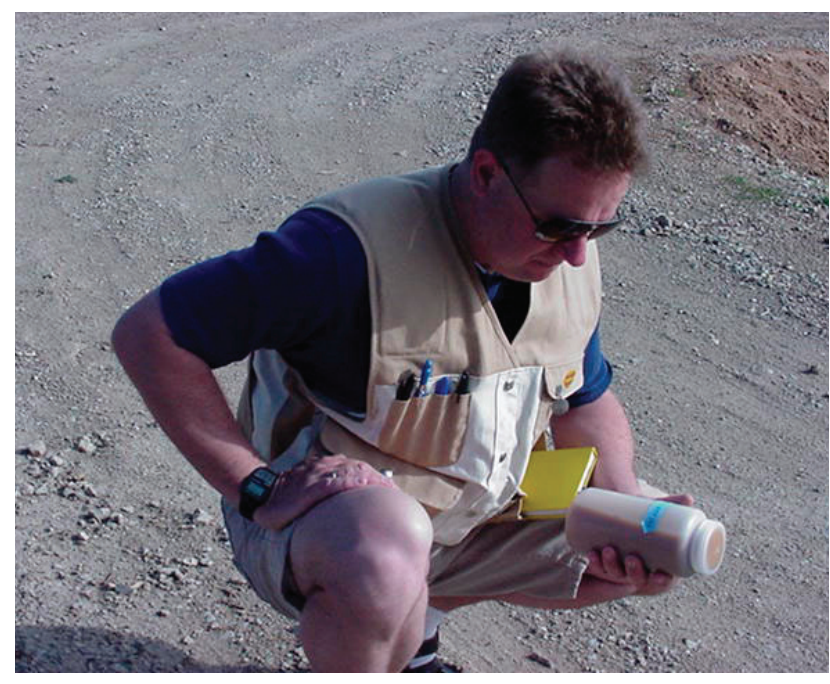

Figure 3. Geoscientist using the USGS FLT to leach a soil sample onsite.

\section{Development of the USGS Field Leach Test}

The USGS FLT is a modification of a leach test developed by Hageman and Briggs (2000). The method was originally developed to quickly assess and predict metals and acid release from historical metal mine dumps. The element concentration trends (geochemical signatures) of the leachates determined by this test were used to rank and prioritize the waste piles for cleanup.
Since its inception, use of the USGS FLT has increased, and the test is now used to predict or characterize the potential for metals and acid release from a diverse variety of geologic materials.

As part of developing the FLT, extensive research and comparative studies were done using many other types of leach tests. After the initial tests, we focused our comparison on studies between the USGS FLT and the EPA Method 1312, Synthetic Precipitation Leaching Procedure (SPLP) (U.S. Environmental Protection Agency, 2002). This comparison was emphasized because the SPLP was one of the leach tests most commonly used for leaching studies of mine wastes. Complete results of this study are given in Hageman and Briggs (2000).

Comparison of the two procedures showed that the 5-minute USGS FLT produced leachate geochemical signatures and element-concentration trends that are similar to those produced by the 18-hour EPA (SPLP) test. As a result of these studies, the USGS adopted the USGS FLT as a screening procedure that can be used as a surrogate for the EPA (SPLP) procedure.

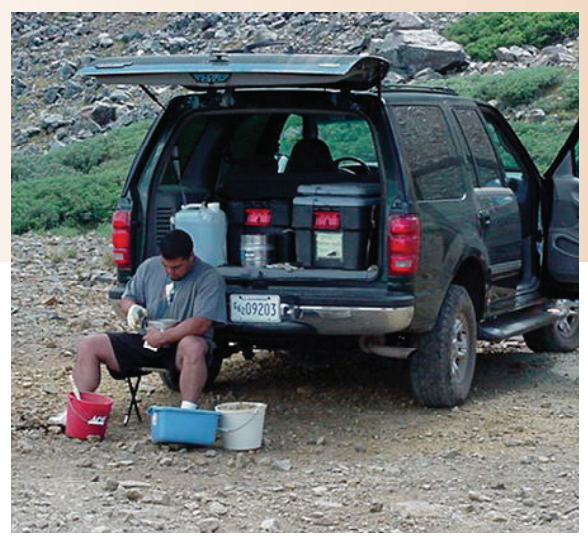

Figure 4. Geoscientist using the USGS FLT to sieve and mix a sample for leaching onsite.

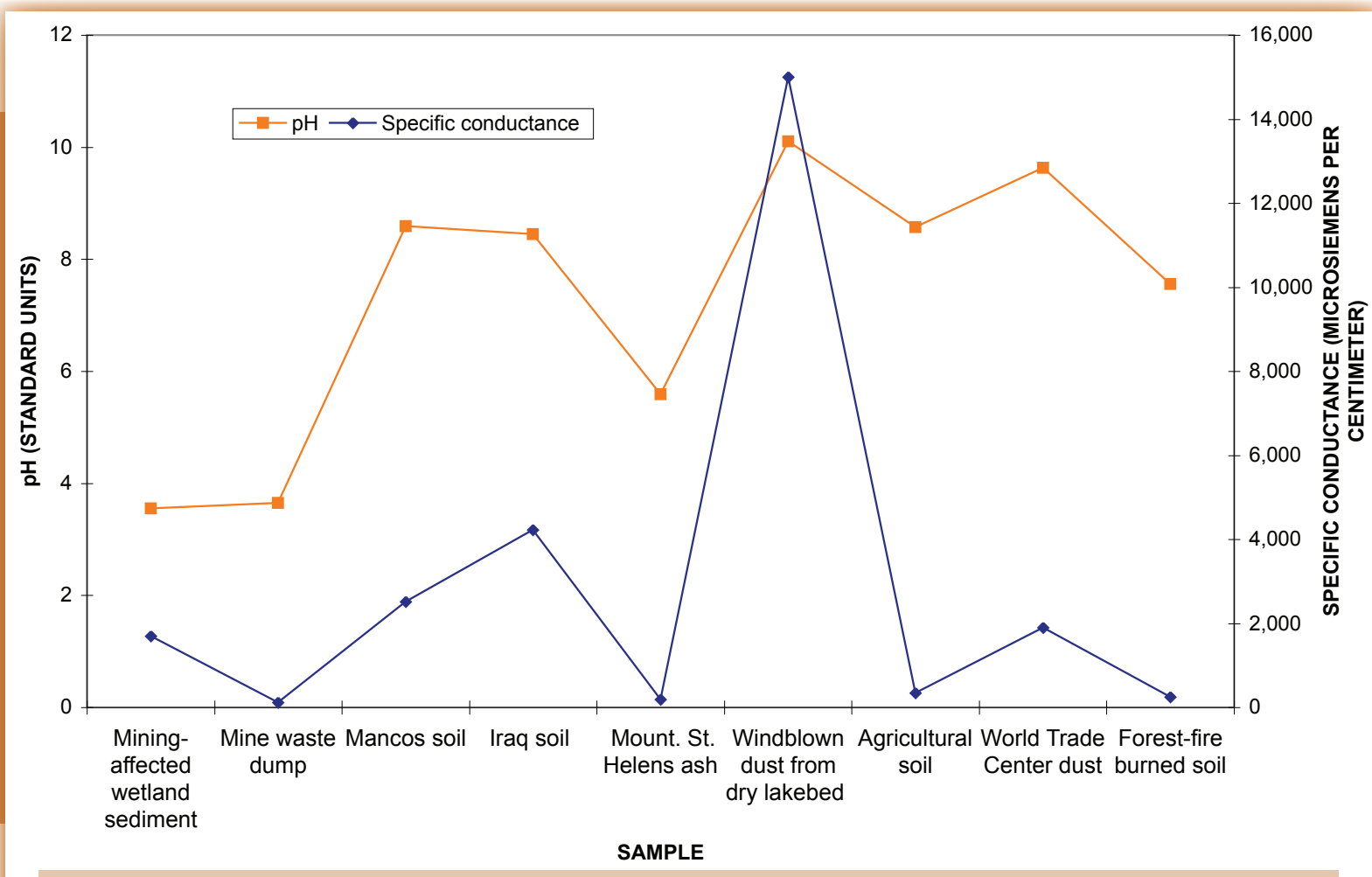

Figure 5. Leachate $\mathrm{pH}$ and specific-conductance data for a variety of samples leached using the USGS FLT. 


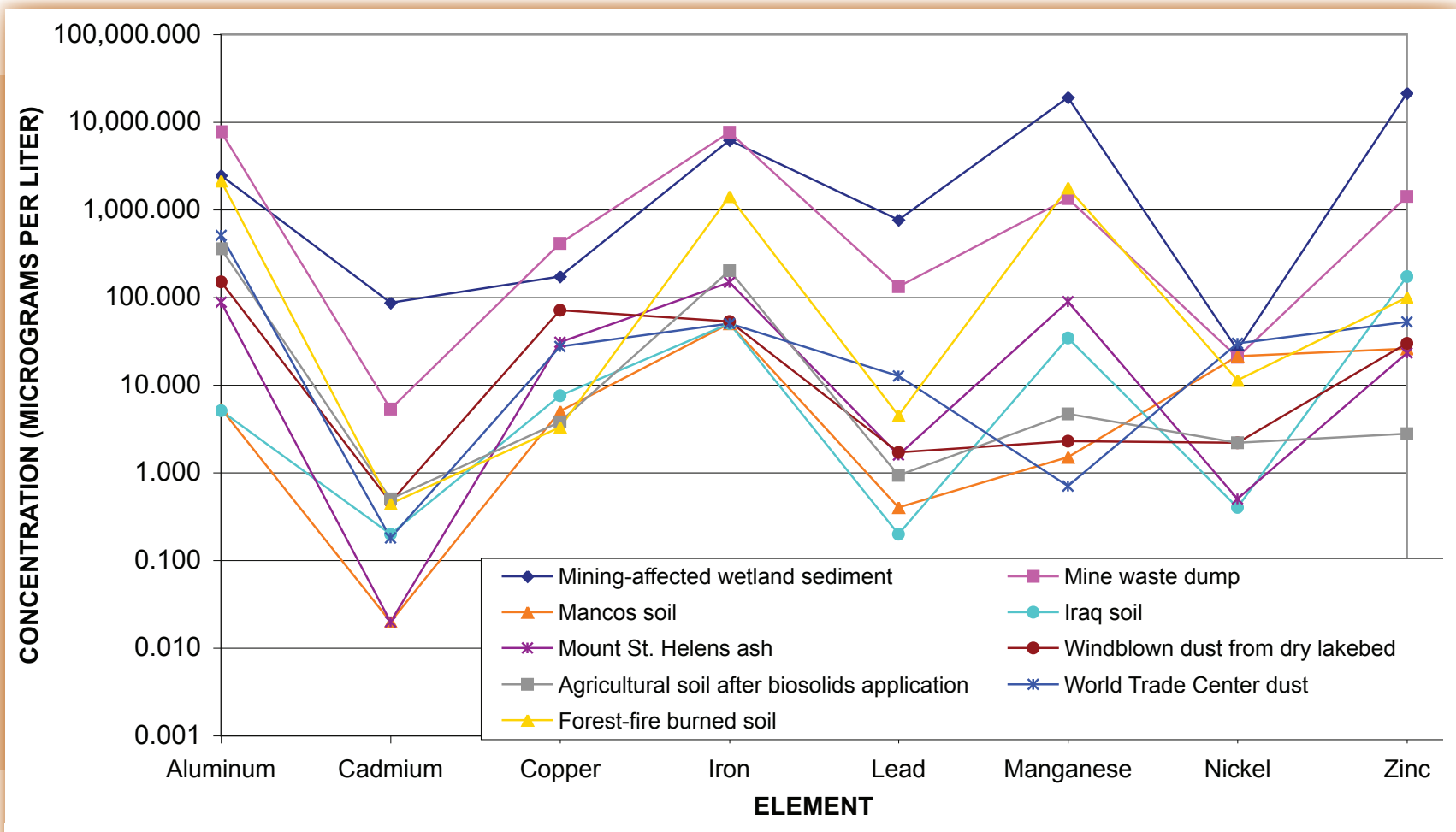

Figure 6. Selected leachate trace-element signatures (ICP-MS) for a variety of samples leached using the USGS FLT.

An important feature of the USGS FLT procedure is that it was designed to use the same extraction ratio (20 parts leachate to 1 part solid) as the EPA (SPLP) leach test. Use of the 20:1 ratio ensures that the soluble components of the sample can be taken into solution without exceeding saturation limits and allows results produced using the USGS FLT to be compared directly with other leaching studies that have used the EPA (SPLP). It also ensures that the FLT provides sufficient sample to obtain all desired measurements and elemental analyses.
A complete listing of the parameters of these two procedures is given in table 1 . Finally, the USGS FLT offers the advantage of convenience. It can easily be performed onsite (fig. 3) or in the laboratory with equipment and reagents that are readily available and can be taken to the field in the back of a vehicle (fig. 4). Onsite leaching requires only the return of the preserved filtrate to the laboratory for analyses. In contrast, the EPA (SPLP) procedure requires specific, costly equipment and must be performed in the laboratory.

Table 1. Leaching parameters of the USGS FLT and the modified EPA Method 1312 (SPLP). $[<$, less than; , approximately]

\begin{tabular}{|lll|}
\hline Parameter & Modified EPA 1312 (SPLP) & USGS FLT \\
\hline Test type & batch & batch \\
\hline Leachate to solid ratio & $20: 1$ & $20: 1$ \\
\hline Leachate composition & $60 / 40 \mathrm{H}_{2} \mathrm{SO}_{4} / \mathrm{HNO}_{3}$ & deionized water \\
\hline Particle size used & 4.2 (for mine wastes) & $\sim 5.7$ \\
Sample mass & $<1$ centimeter & $<2$ millimeters \\
\hline Duration of agitation & 100.0 grams & 50.0 grams \\
\hline Agitation method & 18 hours & 5 minutes \\
Filtration & end-over-end rotary & hand shaken \\
Filter type & positive pressure & syringe \\
Filter pore size & borosilicate glass fiber & nitrocellulose \\
\hline
\end{tabular}

\section{Some of the Studies That Have Used the USGS FLT}

In addition to studies of metal mine wastes (see, for example, Hageman, 2004), the USGS FLT has been used extensively for a variety of other applications, including environmental studies of the World Trade Center area after the September 11, 2001, attack (Clark and others, 2001; Plumlee and others, 2005); studies of the effects of surface applications of biosolids on soil, crops, ground water, and streambed sediment (Yager and others, 2004); as well as leach studies of mine dump cores, naturally mineralized soils, forest-fire burned soils, dried chemical slurries (used to fight forest fires), various types of eolian dusts, volcanic ash, and dried stream and wetland sediments. Examples of some of the leachate geochemical data produced from these studies are given in figures 5 and 6 .

Over time, these studies have shown the USGS FLT to be effective as a quick and inexpensive method to characterize chemical reactivity and identify the water-soluble fraction of very diverse geologic sample matrices. 


\section{Procedure for Using the USGS Field Leach Test}

The first step in the USGS FLT is to collect a representative sample. After collection, the sample is air dried, if necessary, and dry sieved as desired (less than 2 millimeters for most samples). Some samples do not need to be sieved (for example, dusts).

To leach, 50.0 grams of prepared sample is weighed into a 1-liter (L) plastic bottle. Approximately $1.0 \mathrm{~L}$ deionized water is added slowly so that no dust is lost. (Depending upon the amount of solid material available, other leachate volumes can be used as long as the 20:1 water-to-solid ratio is maintained.) The bottle is capped and vigorously hand shaken for 5 minutes. The contents are then allowed to settle for approximately 10 minutes. After settling, subsamples of the leachate are measured for $\mathrm{pH}$, specific conductance, and other parameters. A portion of leachate is filtered using a $60-\mathrm{cc}$ (cubic centimeter) syringe and a 0.45 -micrometer pore-size nitrocellulose filter. If filtration is difficult, a 0.70-micrometer glass fiber prefilter can be used in conjunction with the 0.45 -micrometer filter in a serial manner. Subsamples of the filtrate are collected and preserved for analysis.

\section{Conclusion}

The USGS FLT has proven to be a valuable tool for a diverse group of investigators including Federal, State, and other governmental agencies, environmental professionals, and academia.

The FLT has been used both onsite and in the laboratory and has proven effective for the characterization of diverse geologic and environmental materials for a variety of geochemical, environmental, and toxicological investigations.

Leachate geochemical signatures produced using this test have proven to be a critical and integral part of these diverse investigations.

\section{References Cited}

Clark, Roger N., Green, Robert O., Swayze, Gregg A., Meeker, Greg, Sutley, Steve, and others, 2001, Environmental studies of the World Trade Center area after the September 11, 2001 attack: U.S. Geological Survey Open-File Report 01-0429.

Hageman, Philip L., 2004, Use of short-term (5-minute) and long-term (18-hour) leaching tests to characterize, fingerprint, and rank mine waste material from historical mines in the Deer Creek, Snake River, and Clear Creek watersheds in and around the Montezuma Mining District, Colorado: U.S. Geological Survey Scientific Investigations Report 2004 -5104, 41 p.

Hageman, Philip L., and Briggs, Paul H., 2000, A simple field leach for rapid screening and qualitative characterization of mine waste material on abandoned mine lands, in ICARD 2000, Proceedings from the Fifth International Conference on Acid Rock Drainage, Denver, Colorado, May 21-24, 2000: Society for Mining, Metallurgy, and Exploration Inc., p. 1463-1475.
Plumlee, G.S., Hageman, P.L., Lamothe, P.J., Ziegler, T.L., Meeker, G.P., Brownfield, I., Adams, M., Swayze, G.A., Hoefen, T., Taggart, J.E., Clark, R.N., Wilson, S., and Sutley, S., 2005, Inorganic chemical composition and chemical reactivity of settled dust generated by the World Trade Center building collapse, in Urban aerosols and their impactsLessons learned from the World Trade Center tragedy: American Chemical Society Special Publication, p. 238-276.

U.S. Environmental Protection Agency, 2002, Test methods for evaluating solid wastes, physical and chemical methods: http://www.epa. gov/epaoswer/hazwaste/test/sw846. htm, accessed 07/25/2005.

Yager, Tracy J.B., Smith, David B., and Crock, James G., 2004, Effects of surface applications of biosolids on soil, crops, ground water, and streambed sediment near Deer Trail, Colorado, 1999-2003: U.S. Geological Survey Scientific Investigations Report 2004-5289, $98 \mathrm{p}$.
For additional information on any aspect of this method, please contact:
Philip L. Hageman
U.S. Geological Survey
Bldg. 20 MS 964 DFC
Denver, Colorado USA
80225-0046
Telephone: (303) 236-2494
Fax: (303) 236-3200
Email: phageman@usgs.gov 